\title{
Apatia e Alheamento Político numa Sociedade Paralisada: os limites da nova democracia chilena
}

\author{
Edward C. Epstein \\ University of Utah
}

\begin{abstract}
Resumo
A noção de "sociedade paralisada" usada aqui para descrever a democracia chilena contemporânea pretende sugerir um determinado sistema político em que a probabilidade de mudança significativa resultante de eleições e negociações foi reduzida a um mínimo. Tendo em vista os dispositivos políticos restritivos impostos pelo regime militar de Pinochet à nova democracia, tais como a figura dos senadores nomeados e a lei eleitoral "binomial" que aumenta de modo muito desproporcional a representação do maior grupo minoritário pode-se afirmar que o poder político estava destinado a ser dividido quase igualmente entre as forças de centro e centroesquerda agrupadas na coalizão da Concertación e seus oponentes da direita, num aparente desrespeito à vontade dos eleitores. A questão central deste artigo se relaciona com os efeitos prováveis que este imobilismo político pode ter sobre os chilenos à medida que eles se conscientizem de que as forças políticas que representam uma maioria popular têm capacidade limitada para realizar as mudanças desejadas. O tipo de efeito sugerido aqui se concentra na apatia e no alheamento político existentes.
\end{abstract}

Palavras-chave: democratização, apatia política, imobilismo político, Chile

\section{Abstract}

The notion of a "stalemate society" used here to describe contemporary Chilean democracy is meant to suggest a particular political system where the likelihood of significant change resulting through elections and bargaining has been reduced to a minimum. Given restrictive political provisions imposed by the Pinochet military regime upon the new democracy such as the constitutionally-sanctioned appointed Institutional Senators and the "binomial" election law which dramatically over-represents the largest minority group one can argue that political power was meant to be almost equally divided between those center and center-left forces grouped in the Concertación coalition and those opposing them on the political right, in seeming disregard of what the voters wanted. What is raised as the central question for examination in this essay relates to the likely effects such entrenched political immobilism may have had on Chileans as they became aware that the political forces representing a popular majority had only a limited ability to achieve the changes sought. The type of effect suggested here focuses on existing political apathy and alienation.

Key words: democratization, political apathy, political immobilism, Chile 
A noção de "sociedade paralisada" usada aqui para descrever a democracia chilena contemporânea pretende sugerir um determinado sistema político em que a probabilidade de mudança significativa resultante de eleições e negociações foi reduzida a um mínimo. Tendo em vista os dispositivos políticos restritivos impostos pelo regime militar de Pinochet à nova democracia, tais como a figura dos senadores nomeados e a lei eleitoral "binomial" que aumenta de modo muito desproporcional a representação do maior grupo minoritário (Valenzuela, 1991, pp.50-53; Scully, 1995, p.125), pode-se afirmar que o poder político estava destinado a ser dividido quase igualmente entre as forças de centro e centro-esquerda agrupadas na coalizão da Concertación e seus oponentes da direita, num aparente desrespeito à vontade dos eleitores. ${ }^{1}$ Os esforços para eliminar o que Garretón (1994, p.224) chamou de "enclaves autoritários" da Constituição e tornar o sistema mais representativo foram repetidamente rejeitados pelo Congresso durante a década de 1990 (Garretón, 1994, p.226; Oppenheim, 1999, p.205). A questão central deste artigo se relaciona com os efeitos prováveis que este imobilismo político pode ter sobre os chilenos à medida que eles se conscientizem de que as forças políticas que representam uma maioria popular têm capacidade limitada para realizar as mudanças desejadas.

O tipo de efeito sugerido aqui se concentra na apatia e no alheamento político existentes. Acredito que valha a pena estudar essas reações em termos do que elas podem contribuir para a compreensão dos aspectos mais qualitativos da democratização e da consolidação da democracia no Chile. No nível conceitual, graus variados de apatia e alheamento podem ser vistos como marcadores em um continuum que mede o apoio ao regime e a legitimidade da democracia atual. Do ponto de vista da teoria da participação democrática, níveis significativos de apatia são considerados prejudiciais para a sustentabilidade do regime, uma vez que indicam apoio fraco dos cidadãos (Pateman, 1970). Os momentos de crise econômica, tais como o que ocorreu inesperadamente no Chile em 1999, imediatamente antes da eleição presidencial, são bastante reveladores sobre o funcionamento da democracia (Haggard \& Kaufman, 1995).

\footnotetext{
${ }^{1}$ Apesar de um voto agregado maior para os candidatos da Concertación em todas as eleições legislativas a partir de 1989, a combinação de senadores institucionais nomeados e do uso da fórmula de eleição "binomial" sempre resultou no controle pela oposição da maioria do Senado. Em consequeência, a oposição pode bloquear qualquer legislação que seus membros não aprovem.
} 
Este artigo se divide em quatro grandes seções e uma conclusão. Na primeira seção, apresentam-se e discutem-se estatísticas sobre registro de eleitores, abstenção e votos em branco ou nulos nos dez anos de redemocratização chilena. Na segunda seção, comentam-se os dados de opinião pública sobre apoio à democracia em geral, sobre instituições específicas do Estado democrático e sobre questões particulares. Uma terceira seção analisa a questão do crescente desinteresse pela política expresso por muitos jovens chilenos em idade eleitoral que nunca se preocuparam em se alistar como eleitores. Por fim, a última seção substantiva busca explicar o declínio notável do apoio popular aos partidos políticos, com atenção especial ao enfraquecimento do partido mais importante, o Democrata Cristão. A conclusão aborda o que essas várias tendências indicam em relação à noção sugerida de crescimento da apatia e do alheamento político ligado ao atual regime político. Os números surpreendentemente apertados da recente eleição presidencial de 1999/2000 fazem parte do contexto desses resultados.

\section{Eleições na nova democracia chilena}

A participação eleitoral no Chile, tal como em outros lugares, reflete as circunstâncias institucionais que governam tais atos. Um desses fatos pertinentes é que a atual legislação eleitoral chilena impõe a obrigatoriedade do voto a todos os eleitores registrados, ${ }^{2}$ mas o registro inicial é voluntário (González, 1994 (ed.): Art. 15; Aravena, 1997 , p.6). O alto grau de registro de eleitores e de comparecimento às urnas que marcou o plebiscito de 1988 (quando o eleitorado rejeitou mais um mandato presidencial para

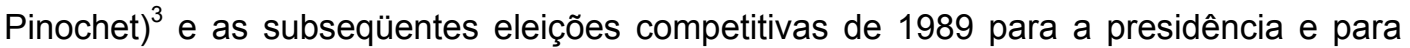
ambas as casas do Congresso sugerem o notável entusiasmo inicial dos chilenos em relação à saída do país da ditadura militar. Contudo, com o tempo, os números da participação diminuíram, à medida que as eleições se tornavam eventos mais normais, em que parecia haver menos em jogo (Lehmann, 1998, p.42). A tabela 1 divide a participação eleitoral no período 1989-2000 em porcentagens de não registrados, abstenção, votos em branco e votos nulos.

\footnotetext{
${ }^{2}$ Multas equivalentes a 50-200 dólares podem ser impostas a quem deixa de votar sem motivo justificado, mas essas multas são geralmente perdoadas por anistias futuras. Alguns municípios são mais ativos do que outros na cobrança de multas (García Rodríguez, 1999).

${ }^{3}$ Cerca de $93 \%$ dos cidadãos em idade eleitoral se registraram para o plebiscito de 1988 e somente $2,4 \%$ deles se abstiveram de votar (Agüero et al., 1998, p.168).
} 
TABELA1

Participação eleitoral no Chile, 1989-2000

\begin{tabular}{|c|c|c|c|c|c|c|c|c|}
\hline & & 1989 & 1992 & 1993 & 1996 & 1997 & 1999 & 2000 \\
\hline \% não registrados & & 7,9 & 8,9 & 10,2 & 15,0 & 15,9 & -- & -- \\
\hline \% abstenção & $\begin{array}{l}P \\
D \\
M\end{array}$ & $\begin{array}{l}2,7 \\
5,3\end{array}$ & & $\begin{array}{r}8,8 \\
8,7 \\
10,2\end{array}$ & & $\begin{array}{l}12,8 \\
12,3\end{array}$ & 10,1 & 9,5 \\
\hline$\%$ votos em branco & $\begin{array}{l}P \\
D \\
M\end{array}$ & $\begin{array}{l}1,1 \\
2,4\end{array}$ & 3,0 & $\begin{array}{l}1,9 \\
3,5\end{array}$ & 3,4 & 4,2 & 0,8 & 0,6 \\
\hline$\%$ votos nulos & $\begin{array}{l}P \\
D \\
M \\
\end{array}$ & $\begin{array}{l}1,5 \\
2,7\end{array}$ & 6,0 & $\begin{array}{l}3,7 \\
5,3\end{array}$ & 7,9 & 13,5 & 2,2 & 1,4 \\
\hline
\end{tabular}

Notas: $P=$ eleição presidencial; $D=$ eleição de deputados; $M=$ eleição municipal

*Primeiro turno ** Segundo turno -- Sem informação

Fontes: "\% não registrados" calculada a partir de dados publicados em Temas Públicos, citado em Lehmann 1988:43, e Ministerio del Interior 2000, exceto para 1997, que vem de Servicio Electoral 1998:9; "\% abstenção", "\% votos em branco" e "\% votos nulos", todos de Ministerio del Interior 2000, exceto "\% abstenção" para 1989, que vem de Servicio Electoral 1998:20

O total dos que não se registraram combinado com o dos que se registraram mas não votaram é considerado como representando os indivíduos que demonstram apatia política. Um survey nacional feito pouco depois das eleições de 1997 indica que os não votantes são desproporcionalmente jovens e com um grau um pouco maior de instrução do que o votante médio (Lehmann, 1998, p.45). ${ }^{4}$ Tendo em vista sua quantidade crescente, essa categoria de jovens não-votantes é suficientemente importante para ser discutida em separado adiante.

Como se poderiam caracterizar os que votaram em branco e os que anularam o voto? Embora se possa presumir uma grande diferença entre esses grupos, com o primeiro sendo motivado pela apatia, enquanto que o segundo indicaria alheamento da política, essa distinção talvez seja um pouco exagerada. Usando dados reconfigurados da mesma pesquisa, ${ }^{5}$ a tabela 2 sugere uma visão um pouco mais complexa.

\footnotetext{
${ }^{4}$ Os que votaram em branco ou nulo eram mais velhos do que os não registrados ou que se abstiveram. Eram semelhantes em idade aos que votaram em algum candidato, um pouco mais do sexo feminino do que aqueles que apoiaram a Concertación, mas semelhantes aos que votaram na oposição, e um pouco mais de classe média do que os eleitores da Concertación, embora menos do que os eleitores da oposição (Lehmann, 1998, p.32).

${ }^{5} \mathrm{O}$ autor agradece a gentileza da sra. Carla Lehmann e do Centro de Estudios Públicos, de Santiago, pelo fornecimento do conjunto de dados sobre as eleições legislativas de 1997 e pela permissão para realizar uma análise secundária das informações.
} 
TABELA 2

Razões para voto em branco ou nulo - Eleição Legislativa de 1997 (\% da coluna)

\begin{tabular}{l|rr}
\hline \multicolumn{1}{c|}{ Razões } & Votos em branco & Votos nulos \\
\hline a. Eu queria protestar contra o sistema & 5,1 & 20,5 \\
b. Os políticos em geral não se preocupam com os & 32,2 & 27,0 \\
problemas do povo & & \\
C. Estou desiludido com o governo atual & 0,0 & 1,6 \\
d. Sou contra o voto obrigatório & 8,5 & 1,6 \\
e. Nenhum candidato me interessou & 37,3 & 31,1 \\
f. Esta eleição não tinha importância & 1,7 & 0,0 \\
g. Os políticos não me interessam & 15,3 & 12,3 \\
h. Não sei em quem votei & 0,0 & 2,5 \\
\hline
\end{tabular}

Fonte: Reconfigurado a partir de Lehmann 1998.

Aqui, as respostas dadas à questão de por que alguém votou em branco ou nulo estão ordenadas, da escolha mais alheada àquela que indica apenas falta de informação, um claro sinal de apatia. Os que anularam o voto têm maior probabilidade de escolher a resposta "a", em que seu ato é diretamente identificado como um "protesto contra o sistema", mas ambos os grupos mostraram quase a mesma probabilidade de apoiar a resposta "b", indicando falta de confiança nos políticos, aqui vista como sugerindo também um grau considerável de alheamento, embora menor do que em "a". Em sentido similar, ambos os grupos tiveram quase a mesma probabilidade de escolher a resposta "e", que não eram atraídos por nenhum candidato, ou a resposta " $g$ ", expressando ausência de interesse por política, as duas opções mais importantes para indicar apatia. O pressuposto original sobre voto em branco versus voto nulo talvez devesse ser modificado para sugerir que os eleitores de ambos os tipos provavelmente indicam uma escala de sentimentos que vão da apatia ao alheamento, ainda que o segundo grupo seja plausivelmente mais marcado pelo alheamento.

Porém, a tendência geral no sentido do crescimento lento da apatia e do alheamento mostrada pelas estatísticas pode ser, ao menos em parte, contestada pelos resultados das recentes eleições presidenciais de 1999-2000, realizadas em dois turnos. Se a abstenção (e provavelmente o não-registro também, como sugeriu El Mercurio, ed. internacional, 11-17 de março de 1999, p. 3; 10-16 de junho, p. 5) continuou a crescer, a quantidade de votos em branco e nulos foi a menor até hoje registrada. $O$ virtual colapso do considerável número de votos nulos que haviam causado tanta preocupação nas 
eleições legislativas de 1997 (El Mercurio, ed. int., 11-17 de dezembro, 1997, p.1; Aravena 1997, p.6; Lagos 1998) deve-se provavelmente à disputa apertada pela presidência e ao aumento das expectativas de que o resultado das eleições poderia trazer mudanças. $O$ primeiro turno terminou no que a imprensa chamou de "empate estatístico" entre o candidato da Concertación, Ricardo Lagos, e o da oposição, Joaquín Lavín, resolvido finalmente no segundo turno. Isso não aconteceu nas duas eleições anteriores, que se definiram no primeiro turno a favor de Patricio Aylwin e Eduardo Frei, ambos democratascristãos. A possibilidade de mudanças significativas com Lagos, o primeiro candidato socialista vitorioso depois de Salvador Allende, será abordada na conclusão.

\section{Democracia, instituições políticas e questões-chave}

As estatísticas eleitorais possibilitam uma visão geral do padrão de lento crescimento da apatia e do alheamento no Chile, mas são menos úteis para conectar essas reações dos cidadãos com possíveis causas políticas. Nesta parte do artigo, a discussão da nova democracia chilena é aprofundada com o uso de uma série de pesquisas de opinião pública feitas ao longo do tempo, com perguntas que investigam a visão geral a respeito do regime democrático, a avaliação das várias instituições políticas que influenciam seu funcionamento e questões políticas específicas dos anos 90 . Esses dados compõem a tabela 3 , onde se podem observar tendências e fazer comparações em cada uma das três categorias mencionadas. 
TABELA 3

Opinião pública chilena 1990-1998 (em \%)*

\begin{tabular}{|c|c|c|c|c|c|c|c|c|}
\hline & 1990 & 1991 & 1992 & 1993 & 1995 & 1996 & 1997 & 1998 \\
\hline $\begin{array}{l}\text { Áreas } \\
\text { a. Satisfação com a democracia } \\
\text { chilena (total de "alguma" e "muita" }\end{array}$ & 75 & 60 & 37 & 44 & 35 & 39 & 44 & 36 \\
\hline \multicolumn{9}{|l|}{$\begin{array}{l}\text { b. Confiança nas instituições } \\
\text { (total de "alguma" e "muita") }\end{array}$} \\
\hline Igreja católica & 76 & -- & -- & -- & -- & 60 & 66 & 63 \\
\hline Banco Central & & -- & -- & -- & -- & 50 & 44 & 41 \\
\hline Carabineiros & 59 & -- & -- & -- & -- & 40 & 40 & 39 \\
\hline Marinha & ** & -- & -- & -- & -- & 39 & 41 & 34 \\
\hline Força Aérea & ** & -- & -- & -- & -- & 39 & 42 & 34 \\
\hline Governo & -- & -- & -- & -- & -- & 35 & 27 & 30 \\
\hline Sindicatos & 48 & -- & -- & -- & -- & 37 & 31 & 30 \\
\hline Polícia investigativa & -- & -- & -- & -- & -- & 29 & 28 & 29 \\
\hline Exército & 41 & -- & -- & -- & -- & 36 & 34 & 29 \\
\hline Administração pública & 49 & -- & -- & -- & -- & 31 & 24 & -- \\
\hline Judiciário & 44 & -- & -- & -- & -- & 25 & 16 & 22 \\
\hline Câmara de Deputados & $* *$ & -- & -- & -- & -- & 26 & 20 & 21 \\
\hline Senado & 63 & -- & -- & -- & -- & 27 & 20 & 20 \\
\hline Partidos políticos & -- & -- & -- & -- & -- & 14 & 14 & 14 \\
\hline \multicolumn{9}{|l|}{$\begin{array}{l}\text { C. Avaliação (em \%) do desempenho } \\
\text { do governo em áreas } \\
\text { selecionadas }^{\star * \star *}\end{array}$} \\
\hline Estabilidade de emprego & +7 & -- & -- & -- & -21 & -2 & -8 & -18 \\
\hline Situação dos Hospitais & +8 & -- & -- & -- & -17 & -8 & -17 & -24 \\
\hline Segurança do cidadão & -23 & -- & -- & -- & -4 & -18 & -58 & -43 \\
\hline Meio ambiente & +29 & -- & -- & -- & +11 & -11 & -23 & -40 \\
\hline Acesso a Moradia & +19 & -- & -- & -- & +12 & +25 & +20 & +11 \\
\hline Oportunidade para os jovens & -- & -- & -- & -- & -19 & -10 & -6 & -28 \\
\hline Qualidade da educação & -- & -- & -- & -- & -- & -- & +22 & +11 \\
\hline Pobreza & -- & -- & -- & -- & -- & - & -24 & -32 \\
\hline Desigualdade social & -- & -- & -- & -- & -- & -- & -24 & -32 \\
\hline
\end{tabular}

Notas: * As pesquisas do CERC aqui utilizadas são amostras por cota realizadas trimestralmente em todas as cidades de 40 mil habitantes ou mais, representativas de cerca de $67 \%$ da população chilena; -- dados inexistentes; ** incluídos com o Exército em "Forças Armadas" *** incluído com Senado em "Parlamento"; **** condições "melhores" (+) menos condições "piores" (-). Fontes: "Satisfação com a Democracia Chilena", Centro de la Realidad Contemporanea [CERC, 1998c; "Confiança nas Instituições", CERC, 1998b, P.104; "Avaliação do Desempenho do Governo", calculado a partir de CERC, 1998 a, p.107.

Como se pode ver, a porcentagem dos que expressam satisfação com a democracia chilena declinou acentuadamente após 1991, com a soma dos que expressam "alguma" ou "muita" satisfação não alcançando mais a maioria do total. Fica claro também que o nível de satisfação sobe nos anos de eleições nacionais, para depois cair de novo. A noção de que os eleitores sentem-se melhor em relação à democracia durante uma campanha de nível nacional será tratada nas conclusões.

É interessante observar que as três principais razões - por ordem de importância - dadas para a insatisfação com a democracia chilena em 1998 eram: "soluções desejadas pelo povo não são implementadas", "o que foi prometido não é feito" e "desigualdades sociais/somente os ricos se beneficiam". As três correspondem a $41 \%$ das 
respostas negativas (CERC, 1998c, p.110). Elas sugerem falta de confiança dos respondentes nos que comandam o sistema democrático.

Do mesmo modo, a confiança popular nas principais instituições declina claramente entre 1990 e os anos mais recentes. A Igreja Católica, os carabineiros (polícia federal) e o Congresso, por exemplo, tinham o apoio da maioria no início da década, mas em 1998, somente a Igreja continuava merecedora de confiança da maioria dos cidadãos. De grande importância é a posição extremamente baixa ocupada nas últimas pesquisas pelo judiciário, por ambas as casas do Congresso e pelos partidos políticos. Em particular, os partidos receberam a confiança pública mais fraca, com somente $14 \%$ dos entrevistados expressando "alguma" ou "muita" confiança neles. O papel dos partidos na democracia chilena é tratado com mais detalhes adiante.

O mesmo quadro negativo reaparece quando se pede ao povo para avaliar as áreas de atuação do governo. A medida citada na tabela 3 é uma tentativa de comparar as respostas positivas com as negativas, subtraindo as segundas das primeiras. $O$ resultado é então apresentado positivamente (indicado por um "+") ou negativamente (por um "-"). O desempenho do governo foi uniformemente classificado como positivo em 1991 em todas as áreas, exceto "segurança do cidadão", mas o nível de satisfação declinou significativamente em anos recentes. Em 1998, apenas "acesso à moradia" e "qualidade da educação" receberam uma avaliação positiva. A "segurança" ainda era vista como a área menos satisfatória quando se tornou uma questão-chave das eleições de 1999-2000, mas tinha agora a companhia do "meio ambiente", "situação dos pobres" e "desigualdade social". Deve-se observar que a pobreza foi foco de uma atenção oficial considerável nos governos de Aylwin e Frei e a eqüidade foi posta ao lado do crescimento econômico no slogan da campanha da Concertación de 1989 (Ruiz-Tagle, 1997; Mideplan, 1999; Epstein, 1997, pp.3-6). A eqüidade voltaria como tema eleitoral na campanha de Lagos de 1999 (El Mercurio, ed. int., 6-12 de janeiro, 2000, p. 4). Embora parte da insatisfação popular com a maioria das políticas do governo possa refletir a exaustão natural de uma coalizão governante depois de dois mandatos consecutivos (Agüero, 1999, p.2), parece haver uma percepção de que muitas dessas políticas não foram especialmente eficazes.

Os dados de opinião pública aqui registrados sobre a democracia chilena, suas instituições e seu desempenho em várias áreas sugerem um padrão geral de distanciamento dos cidadãos em relação ao sistema político, às vezes acusado de uma abordagem elitista/tecnocrata das decisões políticas (Garretón, 1994, p.228; 1999, pp.1112; Baño, 1997 a, pp.20-21). São os mesmos cidadãos que, diante da opção "em geral o país está sendo administrado por uns poucos interesses em busca de seu benefício próprio" ou "para o benefício do povo", escolheram em $82 \%$ dos casos a alternativa mais cínica em 1998. Ao contrário, em 1990 a resposta mais idealista ganhou por uma margem de 48 a 39\% (CERC, 1998b, p.65). Muitos dos que dirigem o Chile agora não parecem gozar de tanta confiança do cidadão médio como no início do atual período democrático. 
As pesquisas do CERC mostram o interesse público pela política começando em níveis bastante modestos e depois declinando fortemente a partir de 1995. Os que afirmam se interessar "muito" ou "um pouco" pela política viram sua participação no total cair de 46\%, antes das eleições de 1989, para algo entre 23 e $26 \%$ no período 1995-98. Do outro lado, os que expressam "nenhum interesse por política", cresceram de $27 \% \mathrm{em}$ 1989 para $40-47 \%$ durante o governo Frei (CERC, 1998c, p.96). ${ }^{6}$ Os números para os anos recentes indicam um grau de apatia política quase análogo ao da soma dos não registrados para votar em 1997 a todas as abstenções, todos os votos em branco e muitos votos nulos. Como mostrarei a seguir, níveis altos de apatia são especialmente característicos de muitos jovens chilenos que demonstram um desinteresse crescente pela política convencional.

\section{Política democrática e os jovens}

A baixa participação política dos jovens chilenos é facilitada pela natureza voluntária do registro eleitoral. Um número cada vez maior dos que atingem a idade adulta não se preocupa em se alistar. A tabela 4 divide a porcentagem dos eleitores por faixa etária para as eleições de 1989, 1993 e 1997.7

\section{TABELA 4}

\section{Voto por idade ao longo do tempo (\%)}

\begin{tabular}{|c|c|c|c|}
\hline $\begin{array}{rr}\text { Eleições } \\
\end{array}$ & 1989 & 1993 & 1997 \\
\hline Faixa etária & & & \\
\hline $18-29$ & 35,99 & 28,58 & 19,89 \\
\hline $30-39$ & 22,62 & 25,66 & 27,90 \\
\hline $40-49$ & 16,15 & 17,70 & 20,26 \\
\hline $50-59$ & 11,74 & 12,28 & 14,11 \\
\hline $60-69$ & 8,08 & 9,10 & 9,86 \\
\hline 70 e acima & 5,42 & 6,68 & 7,89 \\
\hline Total & 100,00 & 100,00 & 100,00 \\
\hline
\end{tabular}

Fonte: Servicio Electoral de Chile, 1998, P.7

A tabela 4 deixa claro que o declínio contínuo do grupo de 18-29 anos enquanto porcentagem da população total produz o relativo aumento da presença dos eleitores pertencentes às outras faixas etárias.

O efeito do não-registro sobre esse declínio relativo do voto dos jovens é sugerido pela forte queda em números absolutos daqueles na faixa entre 18-19 anos registrados para votar nas mesmas eleições.

\footnotetext{
${ }^{6}$ Uma categoria adicional incluída na mesma questão do CERC era a de "pouco interesse" pela política.

${ }^{7}$ Embora a fonte destes números não identifique claramente o tipo de eleição à qual estão relacionados, pode-se presumir que estas estatísticas correspondem às eleições legislativas ocorridas nestes três anos.
} 
TABELA 5

Registro de eleitores ao longo do tempo para a faixa de 18-19 anos

\begin{tabular}{l|ccc}
\hline Eleições & \multicolumn{2}{|c}{1989} & 1993 \\
\hline Total & $304.599(100,0 \%)$ & $243.985(100,0 \%)$ & $85.586(100,0 \%)$ \\
Homens & $163.588(53,7 \%)$ & $132.410(54,3 \%)$ & $51.623(60,3 \%)$ \\
Mulheres & $141.011(46,3 \%)$ & $111.569(45,7 \%)$ & $33.963(39,7 \%)$ \\
\hline
\end{tabular}

Fonte: Servicio Electoral de Chile 1998:7

O número absoluto dos jovens de 18-19 anos que se registram para votar declinou continuamente de 1989 até 1997, de cerca de 305 mil para apenas 86 mil oito anos depois. Se supormos que o grupo de 18-19 anos da população em geral não encolheu durante esse tempo, trata-se de uma queda muito grande num período muito curto. Está claro que uma grande parte dessa mudança ocorreu nos quatro anos correspondentes aos primeiros dois terços do governo Frei, quando o declínio no registro se acelerou. ${ }^{8}$ Os números da mesma tabela revelam que entre os que não se alistaram havia mais mulheres do que homens e que a relutância delas em votar cresceu mais do que a dos homens ao longo do tempo. É óbvio que os jovens não se interessaram pela política eleitoral no passado recente. Ao contrário, a apatia parece estar bastante disseminada e aumentar entre esses novos cidadãos potenciais.

Ao estudar as atitudes políticas dos chilenos com os dados desagregados por faixa etária, Garretón e Villanueva (1999, p.42, p.46) concluem que as percepções dos jovens raramente são muito diferentes das dos mais velhos. Porém, eles tiveram a opção legal de não se registrar para votar e, assim, optar por ficar fora da política.

Nos anos anteriores ao golpe de 1973, muitos jovens chilenos poderiam se destacar como mais ideológicos e inclinados a assumir atitudes de confronto, mas essas diferenças desapareceram em larga medida nos anos 90 , quando foram absorvidos pelo consenso popular voltado para uma visão mais instrumental da política, caracterizada por expectativas bastante modestas do que agora é possível por meio da democracia atual (Garretón \& Villanueva, 1999, p.47, p.67). Os autores apontam para uma parte da juventude de hoje, os que estão agora na faixa dos 25-29 anos, que foram particularmente afetados pela mobilização em torno do plebiscito de 1988, quando entravam na vida adulta. Embora muitos sejam apáticos ou alheios à política, os que continuam mais idealistas estão mais inclinados a expressar essa atitude mediante atividades patrocinadas pela Igreja, em vez de por meio de partidos políticos (Garretón \& Villanueva, 1999, p.68). Essa escolha reflete provavelmente a posição atual de descrédito dos partidos referida anteriormente.

\footnotetext{
${ }^{8}$ O governo Frei foi considerado por muitos observadores como especialmente inclinado a uma abordagem "tecnocrática", algo que pode reforçar a percepção dos cidadãos de um governo distante do povo (Baño, 1997 a, p.20).
} 


\section{O papel reduzido dos partidos políticos no Chile}

Tendo em vista a importância atribuída à ligação do Estado com a sociedade por uma parte significativa da literatura acadêmica sobre a transição para a democracia e sua consolidação (ver Haggard \& Kaufman, 1995, pp.14-15, p.139, p. 153, p.370), as informações sobre a situação atual dos partidos políticos chilenos parece bastante relevante para este estudo da apatia e do alheamento político. Tal como descrito em uma das fontes, os partidos desempenham um papel muito mais limitado agora do que aquele que tiveram em eventos nem tão antigos, como as mobilizações populares da década de 1980 (Agüero et al., 1998, pp.180-181). Deve-se presumir que é durante uma campanha política efetiva de proporções nacionais que a política consegue sua maior projeção para os cidadãos. Em um estudo das eleições presidenciais de 1993, cerca de 69\% dos cidadãos que expressavam preferência por um dos candidatos afirmaram que nunca foram contatados por algum partido político durante a campanha. ${ }^{9} \mathrm{O}$ mesmo artigo contrastava as campanhas eleitorais dos partidos anteriores ao golpe com as de hoje em termos de substituição da cooperação voluntária de militantes pelos esforços de organizações profissionais contratadas para distribuir panfletos e telefonar para os eleitores (Agüero et al., 1998, pp.174-175). A menor eficácia dessa comercialização das campanhas eleitorais pode ser o motivo do notável sentimento de distância da política revelado por muitos cidadãos. Comentários similares são sugeridos por outros autores com referência a "uma certa autonomia da política que está se tornando um negócio especializado dos políticos" (Baño, 1999, p.13).

Como mostra a tabela 6 , o apoio individual a partidos políticos específicos mudou consideravelmente no período 1989-1998.

\section{TABELA 6}

Apoio individual a partidos políticos, 1989-1998 (em \%)

\begin{tabular}{l|rrrrrrrrrr}
\hline \multicolumn{1}{c|}{ Ano } & 1989 & 1990 & 1991 & 1992 & 1993 & 1994 & 1995 & $1996^{*}$ & 1997 & $1998^{+}$ \\
\hline Partidos & & & & & & & & & & \\
PDC & 38 & 34 & 29 & 32 & 33 & 35 & 28 & 23 & 25 & 22 \\
PPD & 9 & 17 & 16 & 9 & 12 & 8 & 10 & 11 & 9 & 11 \\
PS & 1 & 9 & 5 & 6 & 7 & 7 & 6 & 8 & 7 & 8 \\
RN & 10 & 12 & 10 & 10 & 7 & 7 & 10 & 9 & 9 & 8 \\
UDI & 4 & 6 & 8 & 5 & 4 & 4 & 4 & 6 & 6 & 7 \\
PR & 2 & 2 & 2 & 1 & 1 & 0 & -- & 0 & -- & - \\
PC & 1 & 2 & 2 & 1 & 2 & 2 & 2 & 3 & 2 & 3 \\
Outros & 17 & 1 & 2 & 3 & 3 & 3 & 6 & 5 & 4 & 1 \\
Nenhum & 12 & 9 & 10 & -- & 17 & -- & 22 & 21 & 12 & 22 \\
\hline
\end{tabular}

Notas: PDC-Partido Democrata Cristão; PPD-Partido Pela Democracia; PS-Partido Socialista; RN-Renovação Nacional; UDI-União Democrática Independente; PR-Partido Radical; PC-Partido Comunista.

* média de três meses; + média de dois meses; -- informação inexistente.

Fonte: CERC 1998b:132.

${ }^{9} \mathrm{O}$ interessante é que o mesmo estudo sugere que a televisão pode desempenhar um papel surpreendentemente pequeno na decisão dos eleitores (Agüero et al., 1998, p.176). 
O dado mais importante é a erosão evidente da posição dominante do PDC. Na segunda metade dos anos 90 , seu número de simpatizantes tornou-se quase igual ao da soma dos que apóiam os socialistas e o Partido pela Democracia, os dois grupos que compõem o centro-esquerda da Concertación. O triunfo avassalador de Ricardo Lagos sobre o democrata cristão Andrés Zaldivar na eleição primária de maio de 1999 que escolheu o candidato à presidência da Concertación (El Mercurio, ed. int., 27/5-2/6 1999, pp. 1-2) foi um marco nesse declínio de apoio ao longo de uma década. Após o decepcionante primeiro turno da eleição presidencial mais recente, importantes partidários de Lagos acusaram seus aliados do PDC de não controlar a deserção de seus correligionários mais conservadores para a direita. Essa falta de apoio ao PDC, que forçou o segundo turno de janeiro de 2000, parece ter vindo especialmente de indivíduos de classe média baixa e de classes mais baixas (La Tercera, 13 de dezembro de 1999, ed. na internet). Igualmente significativo é o forte aumento da porcentagem dos chilenos que se declaram independentes de qualquer partido, que praticamente dobrou em dez anos. Essa mudança é paralela à diminuição da confiança nos senadores e deputados entre 1988 e 1998 , de $43 \%$ para $23 \%$ e $22 \%$ respectivamente, e em todos os políticos, de $30 \%$ para $18 \%$, no mesmo período (CERC, 1998b, p.105). A imagem recente muito negativa dos partidos fica clara no aumento de $56 \%$ para 65\%, entre 1996 e 1998, da porcentagem dos chilenos que concordam com a afirmativa de que "os interesses dos partidos têm pouco a ver com os interesses da sociedade" (CERC, 1998b, p.115).

A debilidade da ligação com os partidos políticos que supostamente representam a sociedade pode indicar uma "crise das organizações sociais" caracterizada por "níveis crescentes de desarticulação e até atomização" (Baño, 1999, p.12; 1997b). A percepção disseminada de distância da política sentida por muitos cidadãos e os níveis resultantes de apatia parecem estar ligados, ao menos em parte, à mudança na natureza e na função dos partidos políticos. Os líderes do PDC e do PS parecem ter aprovado a perda do caráter de partidos de massa socialmente enraizados e ao menos tacitamente aceito o modelo de uma sociedade desmobilizada, tal como exigido para o sucesso de uma economia de mercado (Epstein, 1997, pp.2-4; Roberts, 1998, pp.120-121; Oxhorn \& Ducatenzeiler, 1998, p.10).

\section{Conclusão}

O sentimento crescente de distância entre os cidadãos chilenos e o que é supostamente o governo deles refletiu-se tanto na opinião pública como no comportamento eleitoral. Muitas pessoas sentem que têm pouca influência sobre um governo que parece inclinado a evitar o debate público sobre questões controvertidas (Garretón, 1999, p.12). Não surpreende que as eleições nacionais sejam ocasiões em que a satisfação dos cidadãos com sua democracia revive temporariamente, para depois cair quando a política retorna à rotina. É óbvio que durante a campanha eleitoral os políticos e 
os partidos precisam fazer um esforço maior para estabelecer contato com eleitores potenciais. Mas mesmo nesse ponto, as recentes mudanças observadas na percepção dos partidos políticos levantam dúvidas sobre a eficácia desses contatos.

A falta de interesse e a frustração em relação à política parecem ter influenciado o declínio do registro de eleitores entre aqueles que chegam à idade eleitoral, o aumento da taxa abstenção, apesar do voto obrigatório, e o crescimento do número de votos em branco e nulos - pelo menos até a eleição de 1999-2000. Considero esse comportamento eleitoral uma indicação do crescimento da apatia política e até mesmo de algum alheamento da política.

Embora seja provável que uma parte da abstenção crescente e do não registro possa simplesmente refletir uma satisfação básica com o modo como a democracia chilena administrou a economia antes da recessão de 1999, as informações oferecidas aqui sugerem que muitos chilenos têm relativamente pouca confiança na maioria de suas instituições básicas e questionam a atuação do governo em muitas áreas da administração.

A tabela 7 apresenta dados comparativos entre países sul-americanos sobre três questões possivelmente relacionadas, consideradas relevantes para a discussão do que poderia ser chamado de "qualidade" da democracia chilena: baixo interesse dos cidadãos pela política, eficácia percebida do voto e importância presumida dos militares na política.

TABELA 7

A democracia chilena em comparação

\begin{tabular}{l|ccc}
\hline Democracia & Baixo interesse em política (\%) & $\begin{array}{c}\text { Eficácia do voto } \\
(\%)^{* *}\end{array}$ & $\begin{array}{c}\text { Poder dos militares } \\
(\%)^{* * *}\end{array}$ \\
\hline Argentina & 77 & 63 & 5 \\
Bolívia & 79 & 51 & 22 \\
Brasil & 77 & 60 & 20 \\
Chile & 81 & 49 & 40 \\
Colômbia & 75 & 43 & 28 \\
Equador & 73 & 58 & 46 \\
Peru & 75 & 52 & 36 \\
Venezuela & 83 & 49 & 49 \\
\hline
\end{tabular}

Notas: * "Baixo interesse em política é medido somando as respostas "pouco interesse" e "nenhum interesse"; ** "Eficácia do voto" está baseado naqueles que pensam que votar pode trazer um futuro melhor; ${ }^{* * *}$ "Poder dos militares" reflete a escolha dessa instituição como uma das mais poderosas do país.

Fonte: Apoyo Opinión y Mercados 1997:20, 23, citando Latinobarômetro 1996.

A comparação das respostas chilenas com as de outras democracias da América do Sul no mesmo ano de 1996 indica que a situação política no Chile pode ser um pouco pior do que em outros casos. Entre as oito democracias pesquisadas, o Chile ocupa o segundo lugar em "baixo interesse pela política", empatou em segundo lugar em baixa "eficácia do voto" e ficou em terceiro na questão sobre "influência dos militares". 
Em termos das noções mais gerais de democracia (ver Karl, 1991, pp.164-165), pode-se afirmar que o atual arranjo institucional chileno tem aspectos que degradam sua essência de democracia plenamente significativa. Dito em linguagem consoante com os dados de pesquisas aqui apresentados, a influência militar constante sobre questões políticas importantes pode produzir o sentimento de que o resultado das eleições dificilmente irá mudar o Chile para melhor, reduzindo assim o interesse dos cidadãos pelos processos políticos. Tal como sugeri no início deste artigo, o que muitos chilenos percebem hoje é uma "sociedade paralisada", em que o voto dificilmente produzirá mudanças importantes no equilíbrio do poder, situação que traduz provavelmente o que os conselheiros militares pretendiam quando criaram a atual Constituição e as peculiares regras eleitorais vigentes a partir de 1989 (Bosworth \& Munck, 1997, pp.9-10).

Os dois turnos da eleição presidencial de 1999-2000 introduzem algumas variações no padrão de participação política discutido aqui, tendo em vista a forte queda ocorrida no número de votos em branco e nulos. Devem os chilenos interessados pela situação de sua democracia continuar preocupados com o que foi interpretado anteriormente como sinais de apatia e alheamento políticos, ou os resultados da eleição legislativa de 1997 devem ser considerados um fenômeno passageiro? Em nossa visão, é preciso aprofundar a discussão para compreender melhor as últimas eleições.

Uma resposta superficial sobre a saúde da democracia chilena atribui a mudança no comportamento eleitoral ao quase empate do primeiro turno e o conseqüente interesse gerado por esse resultado. Por sua vez, muitos observadores procuraram explicar o empate em termos da recessão inesperada de 1999 que causou um desejo de punir a Concertación com um voto na oposição (Cavallo, 1999), ou em termos do medo que os mais conservadores podem ter sentido diante de um candidato socialista. Embora essas análises não estejam erradas, elas talvez não dêem conta da sutileza do que provavelmente aconteceu.

De uma perspectiva um pouco diferente, este artigo procura ligar importantes aspectos de estilo da campanha recente à mencionada queda no número de votos em branco e nulos e oferecer uma explicação mais profunda do que aconteceu. Desse ponto de vista, Lavín, de forma muito astuta, decidiu não somente se distanciar dos partidos políticos impopulares, fazendo uma campanha independente, como fez um esforço concertado para se aproximar de partes da população em geral. Logo de início, utilizou um questionário distribuído em lugares públicos ou feito por telefonemas aleatórios que perguntava aos chilenos sobre as necessidades percebidas (El Mercurio, ed. int., 8-14 de abril, p. 4). Quando perguntaram a Lagos sobre essa consulta pública aos eleitores que se sentiam isolados ou ignorados pelos partidos tradicionais, o candidato da Concertación parece não ter percebido o que estava acontecendo, respondendo que todos sabiam quais eram os principais problemas do país. Depois, enquanto Lagos passava semanas tentando resolver os conflitos entre os diferentes partidos de sua coalizão, Lavín conquistava eleitores com sua bem divulgada "caminata" com pequenos grupos de 
cidadãos em todo o Chile, discutindo os problemas locais face a face com o povo ( $E$ I Mercurio, ed. int., 8-14 de julho, p. 4; Agüero 1999:2). Somente depois que perdeu quase toda a vantagem no surpreendente primeiro turno de dezembro foi que Lagos procurou "reconquistar as ruas", imitando as táticas personalistas de campanha de Lavín antes do segundo turno de janeiro (El Mercurio, ed. int., 6-12 de janeiro de 2000, p. 4).

$\mathrm{O}$ que sugiro aqui é que muitas das pessoas que em eleições passadas haviam votado em branco ou nulo podem ter-se persuadido a votar em Lavín, atraídas por sua campanha populista que sugeria que ele era diferente dos políticos tradicionais, tão desconsiderados por muitos chilenos. Essa especulação baseia-se na identidade de muitos dos que não haviam apoiado qualquer candidato em eleições anteriores. Em termos de gênero, classe social e nível de instrução, aqueles que votaram em branco ou nulo nas eleições legislativas de 1997 parecem muito mais próximos demograficamente dos eleitores que então apoiaram um candidato de oposição (Lehmann, 1998, p.32). Esses eleitores anteriormente apáticos ou alheados podem ter sido conquistados pelo candidato da oposição na eleição seguinte.

O importante declínio do número dos que votaram em branco ou nulo ainda deixa os observadores da política eleitoral chilena com o problema da ascensão, também em 1999-2000, da abstenção e da quantidade de jovens que não se registraram para votar. Aqueles que escolheram alguma forma de não participação não foram atraídos por Lavín ou por qualquer outro candidato. Eles continuam sendo um segmento importante da população que permanece fora do sistema político, cujo comportamento político se caracteriza aqui como influenciado pela apatia. A pesquisa pós-eleitoral de 1997 utilizada neste artigo sugere que esses não-participantes são demograficamente diferentes daqueles que vão às urnas, mas não votam válido. Eles serão muito mais difíceis de atrair enquanto a política chilena continuar a parecer tão distante das questões que eles julgam importantes.

Se as eleições legislativas de 1997 provocaram uma preocupação talvez excessiva com o grau de apatia e alheamento político, tendo em vista os resultados da eleição presidencial mais recente, mesmo assim ainda há muitos indivíduos com pouco interesse pelo sistema político em funcionamento hoje. Acredito que uma parte significativa do problema se relaciona com as condições de paralisia da sociedade, em que as preferências eleitorais não se traduzem em mudanças políticas desejadas. $O$ terceiro governo da Concertación, chefiado pelo presidente Ricardo Lagos, ainda tem de enfrentar os gargalos institucionais que Aylwin e Frei não conseguiram superar, tais como a presença dos senadores institucionais, o voto "binomial" e o poder dos militares. Com efeito, muitas pessoas podem ser céticas sobre as possibilidades de mudança (Agüero, 2000, p.4). Se Lagos também fracassar, pode-se prever que a quantidade de apatia e alheamento político irá crescer nas eleições futuras, minando a qualidade da nova democracia chilena. A recente recepção entusiástica oferecida pelos militares ao general Pinochet quando de sua volta da detenção na Grã-Bretanha não é um bom augúrio para 
aqueles que esperam que a democracia chilena faça mais sentido para uma grande proporção de seus cidadãos (La Tercera, 4 de março de 2000, versão na internet).

\section{BIBLIOGRAFIA}

AGÜERO, Felipe (1999) Second Round Needed to Break Virtual Tie in Chilean Presidential Election. Miami, North-South Center paper, University of Miami.

(2000) Second Round in Chile: Lagos Wins Third Consecutive Presidential Term (2000-2006) for Concertación. Miami, North-South Center paper, University of Miami.

AGÜERO, Felipe, et al. (1998) Votantes, partidos e informaci6n política: la frágil intermediación política en el Chile post-autoritario. Revista de Ciencia Política, Pontificia Universidad Católica de Chile, Vol. XIX(2):159-193

APOYO OPINIÓN Y MERCADOS (1996) El Perú en el Latinobarómetro 96. Lima, PROMPERU.

ARAVENA, Pamela (1997) Por que 4 millones de chilenos prefieren no votar?: el derecho a automarginarse. El Mercurio, ed. internacional., 18-24 de dezembro.

BAÑO, Rodrigo (1997a) La tranquilidad de un gobierno que descansa en la economía. In ROJAS, Francisco (org.) Chile 96: análisis y opiniones. Santiago, Nueva Serie FLACSO, p.19-28.

(1997b) Apatía y sociedad de masas en la democracia chilena actual. Santiago, Nueva Serie FLACSO.

(1999) La ropa sucia se lava en... la medida de lo posible. In: Análisis del ano 1998: sociedad - política - economía. Santiago, Depto. de Sociología, Universidad de Chile, p. 11-23.

BOSWORTH, Jeffrey, e MUNCK, Gerardo. (1997) Political Parties in Post-Pinochet Chile. Trabalho apresentado no congresso internacional da Latin American Studies Association, Guadalajara, México, Abril.

CAVALLO, Ascanio. (1999) Las 50 claves de las campañas de Lagos y Lavín, La Tercera, 11 de dezembro, edição na internet.

CENTRO DE LA REALIDAD CONTEMPORÁNEA [CERC]. (1998a) Barómetro CERC, Março.

CENTRO DE IA REALIDAD CONTEMPORÁNEA [CERC]. (1998b) Barómetro CERC, Julho.

CENTRO DE IA REALIDAD CONTEMPORÁNEA [CERC]. (1998c) Barómetro CERC, Setembro.

EPSTEIN, Edward. (1997) Organized Labor in the New Chilean Democracy: The Politics of Demobilization. Trabalho apresentado no Congresso Mundial da International Political Science Association, Seul, Coréia do Sul, Agosto.

GARCÍA RODRÍGUEZ, Juan. (1999) Entrevista pelo autor com o Diretor do Servicio Electoral, Santiago, 23 de abril.

GARRETÓN, Manuel (1994). The Political Dimension of Processes of Transformation in Chile. In: SMITH, William, ACUÑA, Carlos, e GAMARRA, Eduardo (orgs.) Democracy, Markets, and Structural Reform in Latin America. New Brunswick, NJ, Transaction/North-South Center, University of Miami, p.217-233.

(1999) Pinochet y las revanchas de la democratización incompleta. Mensaje, Vol. XLVIII, 7-12, (janeiro-fevereiro):. 
GARRETÓN, Manuel, e VILLANUEVA, Tamara, (1999) Política y jóvenes en Chile: una reformulación. Santiago, Corporación Participa.

GONZÁLEZ, Carlos (org.) (1994) Constitución política de la República de Chile actualizada. Santiago, Publiley.

HAGGARD, Stephan e KAUFMAN, Robert. (1995) The Political Economy of Democratic Transitions. Princeton, Princeton University Press.

KARL, Terry. (1991) Dilemmas of Democratization in Latin America. In: RUSTOW, Dankwart e ERICKSON, Kenneth (orgs.) Comparative Political Dynamics. New York, Harper Collins, p. 163191.

LAGOS, Marta. (1998) Chilenos: críticos, no todavía ciudadanos. Mensaje, Vol. XLVII: 466, 5-9 (janeiro).

LEHMANN, Carla. (1998) Estudio nacional de opinión pública n. ${ }^{\circ} 7$, Tercera Serie, Diciembre 1997Enero 1998 (Tema Especial: Situación post elecciones parlamentarias; elecciones 1999). Santiago, Documento de Trabajo n. ${ }^{\circ} 283$, Centro de Estudios Públicos, agosto.

Ministerio del Interior, República de Chile, http://www.elecciones.gov.cl:8000. (2000) Información electoral histórica. Santiago.

Ministerio de Planificación y Cooperación [MIDEPLAN]. (1999) Pobreza y distribución del ingreso en Chile, 1998. Santiago, junho.

OPPENHEIM, Lois. (1999) Politics in Chile; Democracy, Authoritarianism, and the Search for Development. Boulder, CO, Westview.

OXHORN, Philip, e DUCATENZEILER, Graciela. (1998) Economic Reform and Democratization in Latin America. In: OXHORN, Philip e DUCATENZEILER, Graciela (orgs.), What kind of Democracy? What kind of Market? Latin America in the Age of Neoliberalism. University Park, PA, Penn State Press, p.3-19.

PATEMAN, Carol. (1970) Participation and Democratic Theory. Cambridge, Cambridge University Press.

ROBERTS, Kenneth. (1998) Deepening Democracy? The Modern Left and Social Movements in Chile and Peru. Stanford, Stanford University Press.

RUIZ-TAGLE, Jaime. (1997) Pobreza y distribución de ingresos en Chile: evolución en los últimos años. Mensaje, Vol. XLVI: 41-45, (dezembro).

SCULLY, Timothy. (1995) Reconstituting Party Politics in Chile. In MAINWARING, Scott e SCULLY, Timothy (orgs.) Building Democratic Institutions: Party Systems in Latin America. Stanford, Stanford University Press, p. 100-137.

SERVICIO ELECTORAL, CHILE. (1998) Abstención elección parlamentaria 1997. Santiago.

VALENZUELA, Arturo, (1991) The Military in Power. In: DRAKE, Paul e JAKSIC, Ivan (orgs.) The Struggle for Democracy in Chile. Lincoln, University of Nebraska Press, p. 21-72. 